\title{
Seismic Behavior Analysis of High-rise Connected Structure
}

\author{
Ji Dongyu \\ Hunan Urban Construction College \\ Xiangtan, China \\ hnjdy@126.com
}

\author{
Li Xiaofen \\ Zhongyuan University of Technology \\ Zhengzhou, China \\ Li_xiaofen2010@163.com
}

\begin{abstract}
In recent years, high-rise connected structure is a structure form that is used widely, in order to research the structure's dynamic characteristics, and improving the structure's seismic performance. This paper adopts large finite element software ANSYS to establish finite element model of high-rise connected structure, uses dynamic time history analysis method for seismic response calculation, and analyses and explain calculation results. Through the analysis, under the action of Tianjin wave, the maximum horizontal displacement value of high-rise connected structure's 23rd floor is $\mathbf{0 . 0 7 7 6 5 m}$, it appears in $2.26 \mathrm{~s}$; under the action of Tianjin wave, the maximum horizontal acceleration value of high-rise connected structure's 23rd floor is $1.90251 \mathrm{~m} / \mathrm{s}^{2}$, it appears in $1.64 \mathrm{~s}$. Research results show that seismic behavior of high-rise connected structure is good, can satisfy the engineering requirement and as well as can provides a certain theoretical basis for seismic design of high-rise connected structure.
\end{abstract}

Keywords-High-rise connected structure; Dynamic analysis; Time-history analysis; Finite element method; Seismic performance.

\section{INTRODUCTION}

High-rise connected structure is a new type of structure that is developed in recent years[1]. Through setting up the connection between building'towers makes it to be common use of space; at the same time, connected building's distinctive shape can bring strong visual result, and can make building body to be characteristic[2]. High-rise connected structure has been widely used in the country, but at present home and abroad the seismic behavior of such structure system has not yet formed a unified understanding, in a high seismic intensity area design of such structure system lacks enough theoretical basis, test and practical experience[3]. Because high-rise connected structure contains two kinds of complex structure system, enlarged base and twin-tower, at present research of its seismic behavior is less[4]. This paper adopts large finite element software ANSYS to establish the finite element model of high-rise connected structure, uses dynamic time history analysis method for seismic response calculation of high-rise connected structure, and analyses and explain calculation results, research results can provides a certain theoretical basis for seismic design of high-rise connected structure.

\section{SUMMARY}

Engineering example is twin-tower building with enlarged base, construction area is $18425 \mathrm{~m}^{2}$, the building is rectangle in plane view, this building is 23 floors, total height is $92 \mathrm{~m}$. 3 floors at the bottom of this building is the enlarged base, for commercial housing. More than 3 floors of this building is two tower that are symmetrical basically and equal altitude, tower is 20 floors, height of tower is 80 $\mathrm{m}$. This building is connected by connecting body on the 20th floor. Connecting body is reinforced concrete plate, foundation part adopts pile foundation[5].

Seismic fortification intensity of this building is 7 degrees, basic earthquake acceleration designed is $0.15 \mathrm{~g}$, The peak value of earthquake acceleration time history curve is $55 \mathrm{~cm} / \mathrm{s}^{2}$.

\section{CALCUlation MODEL}

\section{A Model Parameters.}

The concrete strength grade for high-rise connected structure is $\mathrm{C} 40$, foundation includes soft soil layer and bedrock layer[6], material properties of which shows in the table 1.

TABLE 1. MATERIAL PROPERTIES FOR CALCULATION MODEL OF HIGH-RISE CONNECTED STRUCTURE

\begin{tabular}{ccc}
\hline Material for calculation model & Density $\left(\mathrm{kg} / \mathrm{m}^{3}\right)$ & Elastic modulus(GPa) \\
\hline High-rise connected structure & 2500 & 32.5 \\
Soft soil layer & 1800 & 0.5 \\
Bedrock layer & 2600 & 50 \\
\hline Material for calculation model & poisson's ratio & Damping ratio \\
\hline High-rise connected structure & 0.2 & 0.05 \\
Soft soil layer & 0.35 & 0.05 \\
Bedrock layer & 0.25 & 0.05 \\
\hline
\end{tabular}




\section{B Element selection.}

In the finite element calculation model of high-rise connected structure, beams and columns adopt Beam188 element, floor and seismic shear walls adopt Shell63 element, elastic boundary adopt Combin14 element, foundation soil adopt Solid45 element[7].

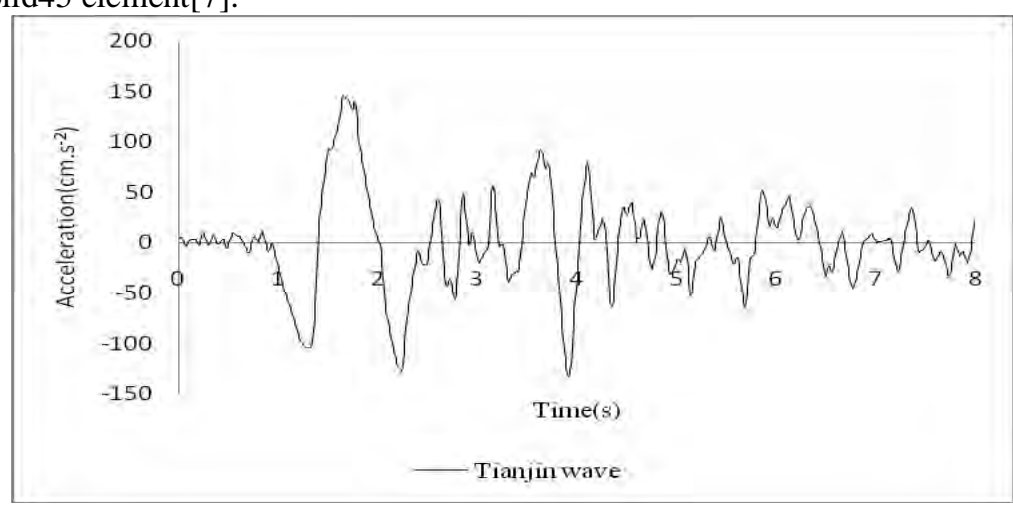

Figure 1. Tianjin wave

\section{Finite element model.}

In order to make real simulation of frame structure teaching building structure'force, the foundation size according to Saint-Venant's Principle[10]. Length of foundation is $508 \mathrm{~m}$, width of foundation is $280 \mathrm{~m}$, depth

\section{Seismic wave selection}

Tianjin wave is a typical seismic record for II, III kinds of subsoil[8-9], characteristic period is $0.3 \sim 0.4 \mathrm{~s}$, under the same seismic waves, Tianjin wave can produce larger seismic response, which shows in the Fig .1. of foundation is $136 \mathrm{~m}$. In the finite element calculation model of high-rise connected structure, $\mathrm{Y}$ direction is height direction, $\mathrm{Z}$ direction and $\mathrm{X}$ direction is horizontal direction, which shows in the Fig .2.

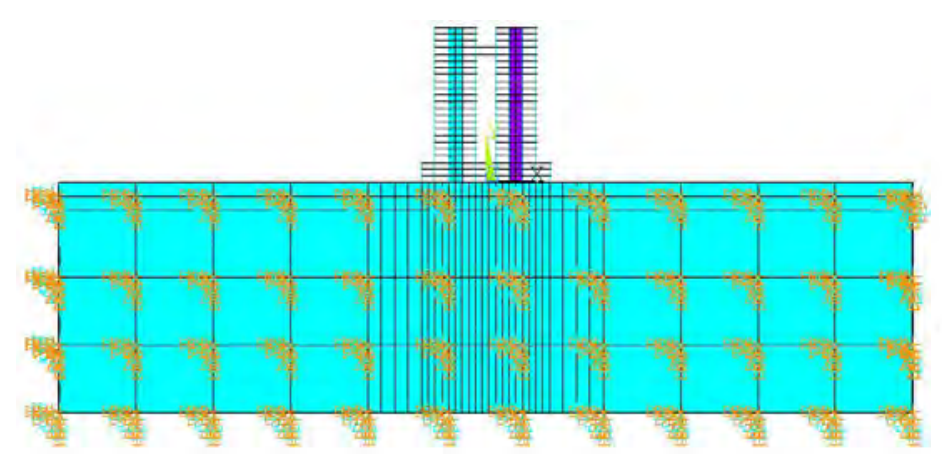

(a)

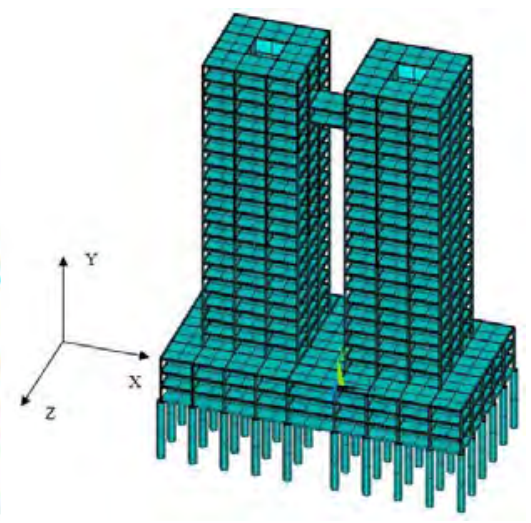

(b)

Figure 2. Calculation model of high-rise connected structure

\section{ANALYSIS OF CALCULATION RESULTS}

This paper adopts large finite element software ANSYS to establish the finite element model of high-rise connected structure, during calculation process, according to corresponding standard, input tianjin wave and uses dynamic time history analysis method for seismic response calculation. This paper selects the twenty-third floor and the third floor as the research object, and analyse the horizontal displacement time history curve and the horizontal acceleration time history curve of high-rise connected structure under earthquake action.

The horizontal displacement time history curve of all top data points for finite element model's twenty-third floor shows in the Fig .3, the maximum horizontal displacement value is $0.078 \mathrm{~m}$, at $2.26 \mathrm{~s}$; the horizontal acceleration time history curve of all top data points for finite element model's twenty-third floor shows in the Fig .4, the maximum horizontal displacement value is 1.90 $\mathrm{m} / \mathrm{s}^{2}$, at $1.64 \mathrm{~s}$.

The horizontal displacement time history curve of all top data points for finite element model's third floor shows in the Fig .5, the maximum horizontal displacement value is $0.006 \mathrm{~m}$, at $4.20 \mathrm{~s}$; the horizontal acceleration time history curve of all top data points for finite element model's twenty-third floor shows in the Fig .6, the maximum horizontal displacement value is $0.69 \mathrm{~m} / \mathrm{s}^{2}$, at $4.45 \mathrm{~s}$. 


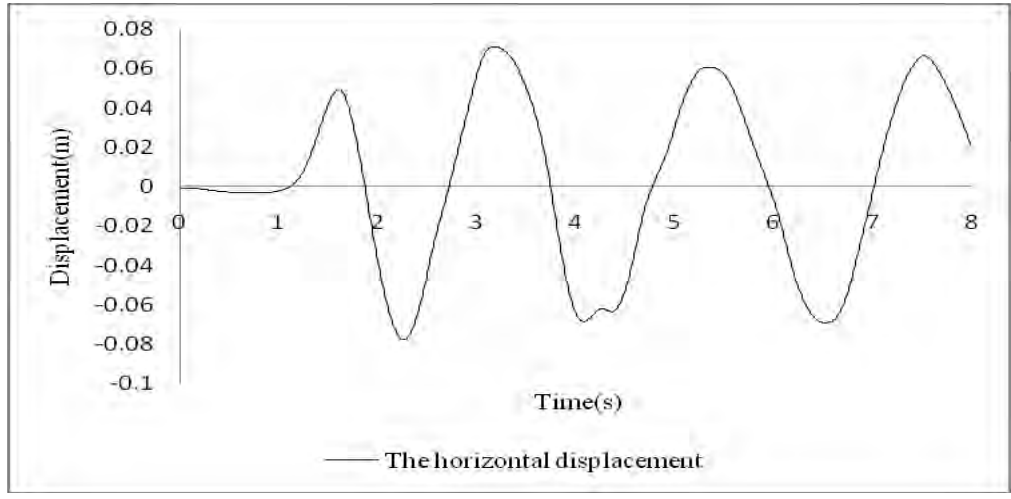

Figure 3. The horizontal displacement time history curve of all top data points for the twenty-third floor

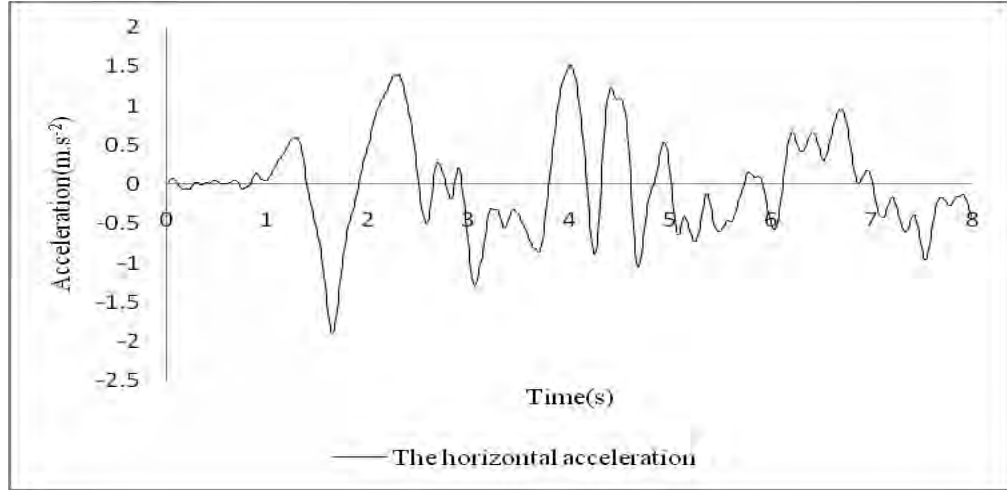

Figure 4. The horizontal acceleration time history curve of all top data points for the twenty-third floor

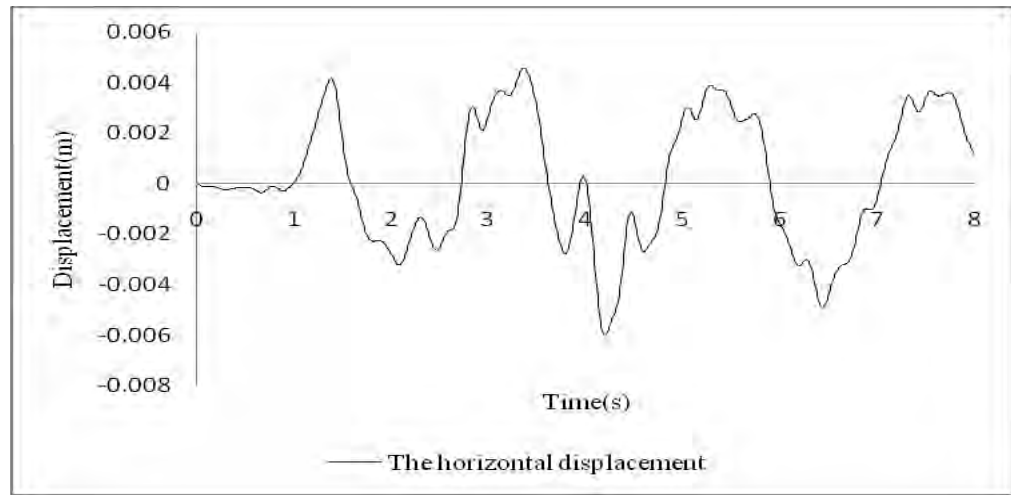

Figure 5. The horizontal displacement time history curve of all top data points for the third floor

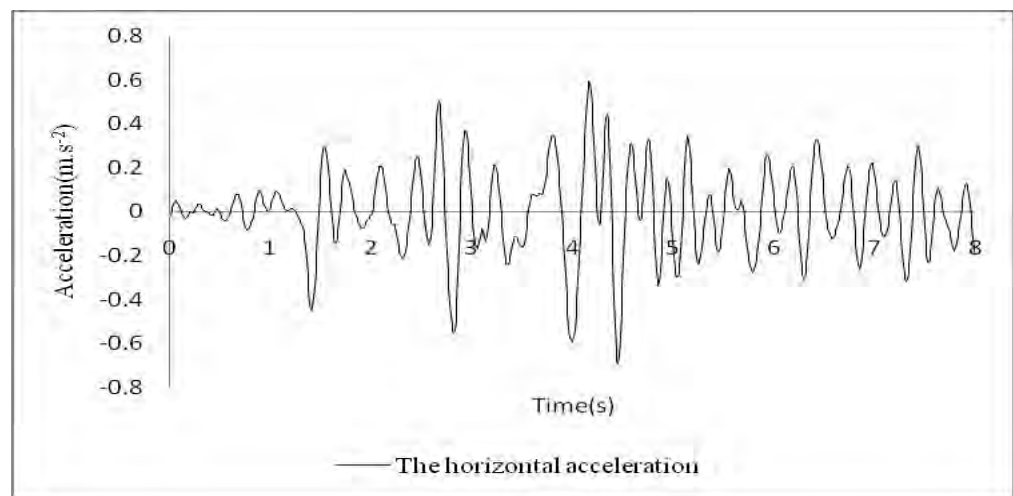

Figure 6. The horizontal acceleration time history curve of all top data points for the third floor

\section{CONCLUSION}

In conclusion,through seismic response calculation analysis of high-rise connected structure, this high-rise connected structure have good seismic behavior, is economic and reasonable, and can satisfy the engineering requirement. 


\section{REFERENCES}

[1] Jianjing Jiang, Xinzheng Lu, Lieping Ye. Finite Element Analysis of Concrete Structures [M]. Tsinghua University Press, 2004.

[2] Xingfu Hu, Feng Xiong, Hui Li. The effect for seismic behavior of the high-rise buildings with twin towers and large chassis by the shear wall's thickness [J]. Sichuan Building Science, 2005(4): 88-90.

[3] Alessandra Fiore,Adriana Netti,Pietro Monaco et al. The influence of masonry infill on the seismic behaviour of RC frame buildings [J]. Engineering structures,2012,44(Nov.):133-145.

[4] Christoph Adam, Clemens Jager. Simplified collapse capacity assessment of earthquake excited regular frame structures vulnerable to P-delta [J]. Engineering structures, 2012, 44(Nov.): 159-173.

[5] Lincy Pyl,Luc Schueremans,Willem Dierckx et al. Fire safety analysis of a 3D frame structure based on a full-scale fire test [J]. Thin-Walled structures,2012,61:204-212.
[6] Zhang, Jing. Optimization of MAC Frame Structure for Opportunistic Spectrum Access [J]. IEEE transactions on wireless communications,2012,11(6):2036-2045.

[7] Xucheng Wang. Finite Element Method [M]. Tsinghua University Press, 2003.

[8] Hua-Peng Chen. Application Of Regularization Methods To Damage Detection In Large Scale Plane Frame Structures Using Incomplete Noisy Modal Data [J]. Engineering Structures, 2008, 30(11): 3219-3227.

[9] Bofang Zhu. Finite Element Method Principle and Application [M] China Water Conservancy and Hydropower Press, 1998.

[10] Tung-Yueh Wu,Wen-Chang Tsai,Jyh-Jone Lee et al. Dynamic elastic-plastic and large deflection analyses of frame structures using motion analysis of structures [J]. Thin-Walled structures, 2009,47(11): 2036-2045. 